\title{
An Empirical Comparison of the Old and Revised Jury Instructions of California: Do Jurors Comprehend Legal Ease Better or Does Bias Still Exist?
}

\author{
John Coleman'1, Russ K. E. Espinoza ${ }^{1}$, Jennifer V. Coons ${ }^{2}$ \\ ${ }^{1}$ California State University, Fullerton, CA, USA \\ ${ }^{2}$ University of California, Riverside, CA, USA \\ Email: ruespinoza@fullerton.edu
}

How to cite this paper: Coleman, J., Espinoza, R.K.E. and Coons, J.V. (2017) An Empirical Comparison of the Old and Revised Jury Instructions of California: Do Jurors Comprehend Legal Ease Better or Does Bias Still Exist? Open Access Library Journal, 4: e3164.

https://doi.org/10.4236/oalib.1103164

Received: January 18, 2017

Accepted: February 14, 2017

Published: February 17, 2017

Copyright $\odot 2017$ by authors and Open Access Library Inc.

This work is licensed under the Creative Commons Attribution International License (CC BY 4.0).

http://creativecommons.org/licenses/by/4.0/

\begin{abstract}
We examined the old (Caljic) and new (Calcrim) standardized criminal jury instructions for the state of California for juror comprehension and objectivity of legal terminology. Three-hundred and twelve native English speaking participants acted as mock jurors and read through a trial transcript that varied juror instructions (Calcrim, Caljic, or non-descript instructions). After completion of the trial transcript, jurors were asked to render a verdict, recommend a sentence, and were questioned on comprehension, the legal definitions of reasonable doubt, circumstantial and direct evidence, and intent. Results demonstrated that jurors comprehended the new instructions significantly better compared with the old instructions. This comprehension was shown by jurors reaching a correct verdict significantly more often with the new instructions compared with the old. It was also shown that jurors could better identify reasonable doubt and evidence significantly better in the new instruction condition compared with the old and non-descript conditions.
\end{abstract}

\section{Subject Areas}

Psychology

\section{Keywords}

Juror Instructions/Comprehension, California Legal Terminology

\section{Introduction}

For many decades researchers have known about the limited comprehension by 
jurors of the legal language used in standardized judge's instructions that are given prior to closing arguments in criminal and civil court cases [1] [2] [3] [4]. The rates of juror comprehension for various legal terms, such as reasonable doubt, circumstantial evidence, and jury nullification, have ranged from as low as $25 \%$ to over $70 \%$ [5]. Most of the confusion regarding legal terminology and the limited juror comprehension is to some extent due to the grammar used in the instructions, lack of legal education by jurors, or even the legalese used in mainstream media. Because it is of paramount importance that jurors understand the instructions that they are given by judges and the legal system to reach a correct verdict that it is imperative that we begin to examine how these instructions influence juror decision making.

In 1999, the American Bar Association [6] sponsored a national survey on attitudes towards the legal system and knowledge of basic legal concepts of 1000 randomly selected participants. Researchers found that $33 \%$ of the respondents believed that the defendant in a trial had to prove his or her innocence rather than the prosecutor, state, or people having to prove a defendant guilty. In a summary of articles by Imwinkelried and Schwed [7], their review of the research on juror comprehension has clearly shown that the average juror in criminal cases comprehends approximately $50 \%$ of the concepts associated with criminal instructions. Yet, in a national poll conducted in the United States on juror duty, it was found that $50 \%$ of the jurors who were called to duty actually showed up, while $92 \%$ of participants polled thought that jury duty was an important social obligation [8]. When only $50 \%$ of the potential jurors actually show up for jury duty and jurors on average only comprehend $50 \%$ of the legal terminology, this would suggest that the legal system's use of jurors may not be fair towards individuals accused of criminal acts.

Due to the poor rates of juror comprehension of the judge's instructions, there have been two solutions suggested as to how to remedy this inadequacy in the justice system. The first solution, according to Ellsworth and Reifman [5], is to do away with the jury system altogether, but this has not been well received and would likely cause even more problems by reintroducing the biasing effects of the presumptiveness of judges. The second solution has been to clarify legal concepts for jurors in the standardized jury instructions to enable better juror comprehension of the law [1] [9] [10]. Psychologists, linguists, sociologists, and various legal professionals have stated and demonstrated that jurors could not understand most of the legal jargon presented in court and that the language can sometimes be confusing to attorneys and lawyers as well [10].

In light of poor juror comprehension, researchers have proposed numerous changes to define and clarify legal concepts and definitions used in standardized instructions to improve juror comprehension [10] [11]. The proposed changes are purported to improve juror comprehension of legal terminology, improve communications between judges and save the courts hours of wasted time [7]. Researchers have proposed guidelines or solutions to amending juror instructions to include correcting or changing grammar use, sentence structure, syntax, 
vocabulary usage, the removal of archaic terminology written in old English or Latin, writing sentences in an active instead of passive form, clearly defining terminology, removal of double negatives, removal of poetic grammar that uses "ly" endings, and using logical organization of concepts [12] [13] [14].

Judges and judiciary committees within the United States legal system turned a blind-eye to the recommendations to change their legal terminology to a set of "Plain-English" instructions that most jurors could comprehend, as was suggested by early researchers, citing that any changes to the jury instructions would alter the meaning of the law and would lead to more cases being filed in appellate courts [5] [10]. However, researchers suggested that the outcomes of the changes to be made are to have a set of "Plain-English" standardized criminal instructions for federal and state courts that are understood by legal and laypersons alike. The instructions should be parsimonious, informative, with comprehendible legal definitions which would ultimately speed juror decision making with fewer errors in judgment and would lead to fewer cases in the appellate courts [10].

All states have some forms of prepared or standardized instructions used in criminal or civil cases. The purpose of these instructions is to reduce the time spent by judges writing individual sets of instructions according to the varying aspects of court cases and to maintain a uniform usage of legal terminology, but judges still maintain the right to change, modify, or not use them at all [15] [16].

On many occasions in the past, the United States Supreme Court has repeatedly set aside judgments in cases where judges have attempted to veer from the standard jury instructions or when the meaning of a legal concept was unclear to jury members [15]. There have been some minor definitional changes to the standard jury instructions in attempts to increase comprehension and to clarify legal concepts, but the goal of the Supreme Court judges has always been to decrease the number of appeals due to confusing legal language and to make a set of universal instructions that the average federal court juror could understand [15].

Before 1990, few state judiciary committees were willing to commit to changing their standardized instructions. However, research has shown that a set of "Plain-English" jury instructions can be written in a way that adheres to legal guidelines with the assistance of researchers in linguistics, psychology, law, and various other social scientific fields for judiciary committees [10]. Judiciary committees in a few states such as Missouri, Illinois, Michigan, and California have made substantial progress in rewriting or renewing their standard juror instructions for both the civil and criminal courts [16].

\section{Standardized State Jury Instructions}

\section{Missouri and Illinois}

In a study of juror comprehension on declarative and procedure knowledge of legal concepts, Hurt [17] found that the average level of juror comprehension was $58 \%$ for Missouri patterned jury instructions. In an article advocating a need 
for "Plain-English" patterned jury instructions, Easley [18] states that mock jurors showed a $10 \%$ increase from $50 \%$ to $60 \%$ in comprehension of the legal concepts of Illinois' patterned instructions when the instructions were rewritten in a clearer form. Furthermore, Easley [18] contends that juror comprehension rates for jury instructions should be $70 \%-75 \%$ and revised instructions should be written at an $8^{\text {th }}$ grade level of understanding.

\section{Michigan}

In Michigan, the Juror Comprehension Project was a study of 600 venire persons recruited to ascertain juror ability to comprehend legal concepts, such as reasonable doubt and evidence, in criminal cases involving either murder or assault [19]. In this study it was found that the percentage of correct responses regarding reasonable doubt was of concern, as the means for the uninstructed jurors clustered around 50\% and respondents believed that any doubt or anything less than $100 \%$ certainty was sufficient for a reasonable doubt to exist. On circumstantial evidence versus direct evidence, it was found that there was almost an $11 \%$ increase in comprehension when instructions were used compared to a no instruction group [19].

Other findings from the Michigan Project were that one third of the respondents thought that intent was not required for a first degree murder charge. These researchers found that Michigan's standard jury instructions did little to increase the ability of jurors to comprehend the criminal instructions as compared to a no instruction group of jurors. However, these same researchers did find that a juror's level of educational attainment was directly related to his or her ability to understand legal concepts [19].

As a result of the Michigan Project, Michigan became one of the first states to take on the task of rewriting their civil and criminal juror instructions through the collaborative efforts of researchers, judges, and lawyers, and by 1991 the State Bar of Michigan had a set of "Plain-English" jury instructions that are periodically updated [5]. The result of Michigan's Standard Jury Instruction Committees efforts was to win the 1993 Clarity Award for writing civil and criminal jury instructions in an easy to understand format by reducing legal terminology to a set of "Plain-English" instructions [5].

\section{California}

According to Tiersma and Curtis [4], California's Judiciary Committee chose not to rewrite their instructions and ignored the research and cries for "Plain-English" instructions that could be understood by the layperson. The reason for not making California's criminal jury instructions simpler was that changing the legal terminology would change the precise wording and thus the nature of the law [4]. The decision to finally rewrite California's standard jury instructions came about as a result of two highly televised trials. The first was the Rodney King beating by police and the second was the murder trial of O.J. Simpson [20].

The general view of the public in California and across the nation in response to the King and Simpson trial verdicts was to blame the jurors for not doing 
their duty and not understanding how to apply the law [20]. Stewart [20] suggests that the general public's disapproval in the O. J. Simpson trial had more to do with race than with juror comprehension. Furthermore, Stewart [20] states that the jurors in both the King and Simpson trials did understand and apply the law as it was intended and that there was a reasonable doubt as to whether Simpson committed murder. The result of these two highly publicized trials was of concern for the California State Judicial Council as members questioned the effectiveness of California's criminal juries [21] [10].

By 1996, the California State Judicial Council set up a task force to undertake revising the civil and criminal jury instructions. However, the committee found that rewriting the instructions was not possible - if the wording was significantly changed in the old instructions the instructions would not retain the intended meaning of the original laws [10]. The committee, therefore, agreed to completely re-write the instructions so a person with a twelfth-grade level of understanding could comprehend the instructions. However, the new instructions are not mandatory to be used by judges who are more comfortable with the older version of instructions [4] [10]. In an online poll conducted by LexisNexis [22], the revised California standardized jury instructions were preferred to the older version by $89 \%$ of Californians who are 18 years of age and older.

\section{Legal Terms}

\section{Reasonable Doubt}

The term "beyond a reasonable doubt" is a good example of legal terminology that is not understood by most jurors. For instance, the verbiage for proof beyond a reasonable doubt varies from state to state and differs from the verbiage that is used in the federal court system [15]. According to Hemmens et al. [15], the term reasonable doubt is a mandatory statement in all criminal court cases across all 50 states, but the terminology used is written in six different forms. The disparity between state and federal interpretations of proof beyond a reasonable doubt and juror confusion has therefore led to the formation of judiciary committees to rewrite their standard juror instructions from the legal babble of legalese into a set of Plain-English instructions that are universally acceptable to lawyers, judges and laypersons alike [10].

In the United States, the term reasonable doubt has been subjected to earlier interpretation and revision by the Supreme Court on many occasions. This was partly due to the way in which the legal language was ambiguous, concepts were not clearly defined, or the legal terminology has been poorly understood by jurors. This has led many researchers and legal professionals to speculate whether jurors were being misguided from rendering a fair and impartial verdict [15] [12].

\section{Circumstantial and Direct Evidence}

Circumstantial evidence is one of the hardest legal terms for jurors to understand. There has been only one article since the new California instructions were written that has compared comprehension of the new instructions to the old 
version. In an article by Tiersma and Curtis [4], 66 undergraduate introductory psychology students at the University of Southern California (USC) were tested using the old (Caljic) and new (Calcrim) versions of criminal jury instructions on the comprehensibility of circumstantial and direct evidence. Two groups were made up of 33 participants each and the participants were mainly female of either White or Asian ethnicity. It was found that the newer version of jury instructions group had a comprehension rate that was approximately $10 \%$ higher compared to the older version group. Overall, the Caljic group had a comprehension rate of $51 \%$, and the Calcrim group had a comprehension rate of $62 \%$, while the comprehension rates for circumstantial evidence was $46 \%$ for the former group and 59\% for the latter group [4].

However, the former research did not simulate a criminal trial. It is important when beginning to restructure these instructions that we have empirical evidence of their applied impact in a field or simulated setting. Therefore, we examined how jurors' decisions are influenced by the type of instructions they receive in a mock jury trial. In order to examine these instructions in more depth we have specifically chosen to include the three California instructions of "murder aforethought", "circumstantial versus direct evidence", and "reasonable doubt" during a mock murder trial. We chose these areas of examination because they are the three areas that have been modified the most from the old Caljic instructions to the new Calcrim instructions.

\section{Juror Attitudes}

If the new instructions lead to a greater understanding of legal terminology compared with the old instructions for jurors, it is imperative that we can demonstrate that this is not due to some other explanation - such as juror attitudes. Though attitudes towards the justice system have been widely investigated in areas such as the death penalty [23], influences of gender and race on juror decision making [24] [25] [26], and insanity [27], there have been no studies to date that relate attitudes towards the criminal system and comprehension of legal terminology [16]. If we are to accurately define how juror instructions contribute to accurate decision making by juror members, then we must rule out other possible explanations, namely the attitudes towards the legal system a juror brings with them in the first place. To rule out juror attitudes as a contributor to juror comprehension of the new instructions, we will measure participant's attitudes with a number of legal attitude measures.

Based on a similar case in the State of California, Los Angeles Superior Court [4] a simulated trial transcript was created that manipulated juror instructions in three ways: the new version (Calcrim), the old version (Caljic), and a non-descript set of instructions. It was first hypothesized that juror comprehension of legal terminology will significantly increase when presented with the Calcrim version of the criminal jury instructions compared to the Caljic version or the non-descript instruction groups. We expect mock jurors in the new Calcrim instructions to answer questions regarding Rules of Evidence, Reasonable Doubt, and Intent/Murder Aforethought correctly significantly more often 
compared with the older Caljic juror instructions. Because the non-descript version was not briefed on the definitions of these legal terms they are expected to score lowest. Second, based on the instructions and the case parameters described within the trial transcript jurors should find the defendant not guilty. We hypothesize that jurors will fully comprehend the new Calcrim instructions and will therefore find the defendant not guilty significantly more often compared with the older Caljic version or the non-descript groups. Lastly, it is hypothesized that these decisions will not be affected by the juror's attitudes towards the legal system for the new Calcrim instructions because these instructions clearly articulate the parameters of a decision in simple language. Because the instructions of the older Caljic version are not clearly defined in terms of basic language, then we would expect jurors to be more ambiguous with their decision making and therefore be more likely to be influenced by their preconceived notions and attitudes towards the legal system.

\section{Method}

\section{Participants}

All participants were Introductory Psychology students enrolled at California State University Fullerton and stated English was their native language. A total of 312 students participated and consisted of 204 females and 108 males ( $M$ age $=20.41$ years, $S D=4.11$, range $=18-59$ years). Thirty-three percent of the participants stated their ethnicity to be Hispanic/Latino, 30\% were of European American descent or "White" non-Hispanic, 17\% were Asian, 3\% were African American, and 17\% were of other ethnicities (Native American, Pacific Islander, Arab, Indian, or mixed Ethnicity).

\section{Materials}

Materials consisted of a trial transcript that described the events and circumstances of a murder, a description of the scene where the murder took place, and included the defendant's plea of Not Guilty. The description of the crime was similar to a case in California where the defendant was found not guilty. Following the trial transcript there were three types of judges instructions. The first set of instructions was the control or non-descript and consisted of general juror instructions regarding deliberation and possible verdicts. The second set of instructions was based on the terminology content used for rules of evidence, reasonable doubt, and intent/murder aforethought from the Caljic instructions. Finally, the third set of instructions was based on the terminology content used for rules of evidence, reasonable doubt, and intent/murder aforethought from the Calcrim instructions.

The questionnaire that assessed participant memory, knowledge, attitudes, and demographics consisted of 156 items. Twenty-five true or false items assessed legal concept comprehension with 13 items for evidence, 8 items for reasonable doubt, and 4 items for murder aforethought or intent. Questions about legal concepts were obtained from the Michigan Project and included items 1 - 8 and 10 - 15 [19]. All other items were from the Tiersma and Curtis [4] original 
study examining juror instructions or were created after consultation with those authors.

Additionally included were three standardized scales that assessed participant attitudes towards the legal system. The purpose of including these instruments was to better examine if juror decisions were most affected by the combined effects of juror instructions and views towards the legal system. The first attitude scale was the Attitudes Toward the Criminal Legal System (ATCLS), which consisted of 38 items that assess integrity, competency, and fairness of the legal system [28]. The second measure of attitudes was the Scale of Attitudes Toward the Legal System (SATLS), which consisted of 36 items that assess general beliefs towards the legal system on two different perspectives: 1) the belief that the system works and 2) cynical beliefs that the system is too lenient [29]. The third measure was the Revised Legal Attitudes Questionnaire (RLAQ), which consisted of 30 items that measured prospective juror bias by determining their attitudes towards the legal system based on 3 specific areas: authoritarianism, equalitarianism, and anti-authoritarianism [30]. Finally, we included various manipulation check questions and demographic questions.

\section{Procedure}

All participants were randomly assigned to one of the three conditions, using SPSS random number generator, as they signed-up to be a research participant. After participants read and signed the consent form, they were then presented with the trial transcript and questionnaire. Participants were instructed to act as real jurors in an actual murder case and they were encouraged to take as much time as they needed to complete the survey. After participants completed answering all of the questions they were debriefed in a thorough and sensitive manner.

\section{Results}

In order to examine juror comprehension of the legal concepts of reasonable doubt, rules of evidence, and murder aforethought an analysis of variance (ANOVA) was conducted. However, because we did not wish to examine the control group who were not instructed with the definitions of legal concepts we conducted the analysis using only the old California juror instructions (Caljic, $\mathrm{N}$ $=156$ ) and the new California juror instructions (Calcrim, $\mathrm{N}=156$ ) participants. As hypothesized, a significant difference was found between the old and the new juror instructions of California for the legal concept of reasonable doubt, $F$ ( 1 , $312)=4.53, p<0.01, \eta^{2}=0.17$. Participants in the new version of the California juror instructions answered significantly more questions correctly for the legal concept of evidence compared with those participants in the old instructions group (see Table 1). Also, as hypothesized, a significant difference was found between the old and the new juror instructions of California for the legal concept of rules of evidence, $F(1,312)=4.92, p<0.01, \eta^{2}=0.18$. Participants in the new version of the California juror instructions answered significantly more questions correctly for the legal concept of reasonable doubt compared with 
those participants in the old instructions group (see Table 1). Finally, we found no significant differences between the old and the new juror instructions of California for the legal concept of murder aforethought, $F(1,312)=2.53, p=0.096$, $\eta^{2}=0.04$.

\section{Juror Instructions and Verdict}

Based on the aforementioned trial in California where the defendant was found not guilty with the new juror instructions a not guilty verdict would also be the correct decision for our case. In order to examine the independent variable of juror instructions and the dependent measure of verdict, a crosstabs chi-square analysis was conducted. There were significant differences for verdict based on juror instructions, $X^{2}(2)=7.21, p<0.05$. Mock jurors found the defendant in the Caljic and non-descript juror instructions conditions guilty significantly more often than those jurors who were in the Calcrim condition (see Table 2). As hypothesized, jurors made correct verdict decisions significantly more in the new Calcrim juror instruction condition than either the Caljic or the non-descript instruction conditions.

\section{Juror Instructions and Legal System Attitudes}

We also wished to examine whether legal attitude measures could provide additional information for juror instructions and whether or not these previously established measures moderate comprehension of the new juror instruction standards and therefore juror decisions. Specifically, we expected jurors who were high in bias on the attitudinal measures (Attitudes Toward the Criminal Legal System, ATCLS, [28]; Scale of Attitudes Toward the Legal System, SATLS, Schiffhauer \& Wrightsman, [29]; and the Revised Legal Attitudes Questionnaire, RLAQ, [30]) would only show bias in the old Caljic instructional groups for legal terminology, and for the Caljic and non-descript instructional groups for verdict.

Table 1. Mean scores for legal concept knowledge by type of jury instruction.

\begin{tabular}{ccc}
\hline & CALCRIM & CALJIC \\
\hline Reasonable Doubt & 7.33 & 6.74 \\
Rules of Evidence* & 5.59 & 4.98 \\
Intent/Murder Aforethought & 2.83 & 2.74 \\
\hline
\end{tabular}

${ }^{*} p<0.05$; Note. Average score for reasonable doubt is the number of correct responses out of 8 . Average score for evidence is the number of correct responses out of 12 . Average score for intent is the number of correct responses out of 5 .

Table 2. Mock juror verdicts.

\begin{tabular}{ccccc}
\hline & & \multicolumn{3}{c}{ Verdict } \\
\hline & Not Guilty & Guilty & Total \\
\hline \multirow{3}{*}{ Condition } & Calcrim Instructions & 73 & 34 & 107 \\
& Caljic Instructions & 57 & 50 & 107 \\
& Non-Descript & 30 & 32 & 62 \\
\hline
\end{tabular}

${ }^{*} p<0.05$. 
Median splits were conducted for each of the three scales (and subscales) of the ATCLS, SATLS, and the RLAQ to determine high and low attributes of the constructs. In order to examine juror comprehension of the legal concepts of reasonable doubt, evidence, and murder aforethought when juror instructions and attitudes are combined separate multivariate analysis of variance (MANOVA) were conducted. A 2 (juror instructions: Calcrim or Caljic) $\times 2$ (high or low on the ATCLS) MANOVA was conducted for reasonable doubt, evidence or murder aforethought. No significant differences based on the combined effects of juror instructions and juror attitudes were found for reasonable doubt, $F(3,308)=$ $1.84, p>0.05, \eta^{2}=0.02$; evidence, $F(3,308)=1.96, p>0.05, \eta^{2}=0.03$; and for murder aforethought, $F(3,308)=0.619, p>0.05, \eta^{2}=0.01$.

A 2 (juror instructions: Calcrim or Caljic) $\times 2$ (high or low on subscale 1 belief the system works\} of the SATLS) MANOVA was conducted for reasonable doubt, evidence and murder aforethought. Significant differences based on the combined effects of juror instructions and juror attitudes were found for reasonable doubt, $F(3,308)=6.21, p<0.05, \eta^{2}=0.21$. Participants in the Caljic condition who were high on subscale 1 of the SATLS were less likely to comprehend the legal terms regarding reasonable doubt (see Table 3 ). However, no significant differences were found for evidence, $F(3,308)=1.45, p>0.05, \eta^{2}=$ 0.01 ; or for murder aforethought, $F(3,308)=0.746, p>0.05, \eta^{2}=0.01$. A 2 (juror instructions: Calcrim or Caljic) $\times 2$ (high or low on subscale 2 \{cynical belief system is too lenient $\}$ of the SATLS) MANOVA was conducted for reasonable doubt, evidence and murder aforethought. No significant differences based on the combined effects of juror instructions and juror attitudes were found for reasonable doubt, $F(3,308)=1.34, p>0.05, \eta^{2}=0.01$; evidence, $F(3,308)=$ 1.38, $p>0.05, \eta^{2}=0.01$; and for murder aforethought, $F(3,308)=0.912, p>$ $0.05, \eta^{2}=0.01$.

Finally, A 2 (juror instructions: Calcrim or Caljic) $\times 2$ (high or low on subscale 1 \{authoritarianism\} of the RLAQ) MANOVA was conducted for reasonable doubt, evidence and murder aforethought. Significant differences based on the combined effects of juror instructions and juror attitudes were found for reasonable doubt, $F(3,308)=7.81, p<0.05, \eta^{2}=0.22$, and for evidence, $F(3,308)$ $=7.22, p<0.05, \eta^{2}=0.22$. Participants in the Caljic condition who were high on

Table 3. Mean scores for legal concept knowledge by type of jury instruction and juror attitudes for subscale 1 belief the system works\} of the SATLS.

\begin{tabular}{ccccc}
\hline & \multicolumn{2}{c}{ CALCRIM } & \multicolumn{2}{c}{ CALJIC } \\
\hline & Low SATLS & High SATLS & Low SATLS & High SATLS \\
\hline Reasonable Doubt* & 7.33 & 6.74 & 5.34 & 5.36 \\
Rules of Evidence & 7.33 & 6.74 & 5.34 & 5.36 \\
Intent/Murder Aforethought & 7.33 & 6.74 & 5.34 & 5.36
\end{tabular}

${ }^{*} p<0.05 ;$ Note. Average score for reasonable doubt is the number of correct responses out of 8 . Average score for evidence is the number of correct responses out of 12 . Average score for intent is the number of correct responses out of 5 . 
subscale 1 (authoritarianism) of the RLAQ were less likely to comprehend the legal terms of reasonable doubt and evidence (see Table 3). However, no significant differences were found for murder aforethought, $F(3,308)=0.746, p>$ $0.05, \eta^{2}=0.01$. A 2 (juror instructions: Calcrim or Caljic) $\times 2$ (high or low on subscale 2 \{equalitarianism\} of the RLAQ) MANOVA was conducted for reasonable doubt, evidence and murder aforethought. No significant differences based on the combined effects of juror instructions and juror attitudes were found for reasonable doubt, $F(3,308)=0.966, p>0.05, \eta^{2}=0.01$; evidence, $F(3$, $308)=1.11, p>0.05, \eta^{2}=0.01$; and for murder aforethought, $F(3,308)=0.899$, $p>0.05, \eta^{2}=0.01$. A 2 (juror instructions: Calcrim or Caljic) $\times 2$ (high or low on subscale 3 anti-authoritarianism\} of the RLAQ) MANOVA was conducted for reasonable doubt, evidence or murder aforethought. No significant differences based on the combined effects of juror instructions and juror attitudes were found for reasonable doubt, $F(3,308)=1.66, p>0.05, \eta^{2}=0.01$; evidence, $F(3$, $308)=1.58, p>0.05, \eta^{2}=0.01$; and for murder aforethought, $F(3,308)=1.22$, $p>0.05, \eta^{2}=0.01$.

\section{Discussion}

The main purpose of this study was to verify that the newly developed criminal jury instructions being used by the state court system of California do indeed increase juror comprehension of legal terminology. Previously, it had been found that there were differences between the usage of the new Calcrim and old Caljic instructions in juror comprehension of the legal term of evidence, but no actual or simulated trial was incorporated into the study [4]. Overall, our findings show significant differences in juror comprehension of legal terminology found between the Calcrim and Caljic instructions based on reasonable doubt and evidence. Jurors in the new Calcrim condition had significantly more correct answers compared with the older version, Caljic instructions, in both reasonable doubt and rules of evidence. The new instructions appear to be clearer for jurors in both comprehension of terminology and ability to execute the instructions in legal cases. However, no significant differences were found between the Calcrim and Caljic instructional groups for intent/murder aforethought. One possible explanation for this finding may be that questions for intent/murder aforethought were minimal and that the phrasing of these questions may have been, linguistically, not fundamentally different. In addition, it may be that the new Calcrim and old Caljic instructions are not substantially different in this area for juror comprehension. Future research should take into consideration that intent/murder aforethought may be a fundamentally different construct compared with reasonable doubt and rules of evidence for juror comprehension and therefore should be explained to jurors in a fundamentally different manner.

In addition, we examined if the old and new instructions influence juror decisions for simulated criminal trials. As hypothesized, we found significantly less guilty verdicts for the Calcrim juror group compared to jurors who received the Caljic or non-descript instructions. According to Wright and Hall [31], it has 
been suggested that there should be fewer guilty verdicts if the legal term of reasonable doubt was understood by jurors, and that fewer guilty verdicts would be due to jurors not wanting to imprison an innocent man.

Finally, it was important to examine if juror attitudes play a role in juror comprehension. We chose the Attitudes Toward the Criminal Legal System (ATCLS; [28]), the Scale of Attitudes Toward the Legal System (SATLS; [29]), and the Revised Legal Attitudes Questionnaire (RLAQ; [30]) because of the consistent research findings demonstrating the reliability and validity of using these scales to examine juror attitudes. Though we found no significant differences based on juror instruction group and the ATCLS, we did find significant differences for the SATLS and the RLAQ. Participants in the Caljic condition who were high on subscale 1 (belief that the system works) of the SATLS were less likely to comprehend the legal terms regarding reasonable doubt. This is interesting because it demonstrates that the old version of the California Juror Instructions (Caljic) can be influenced by juror attitudes significantly more than the new instructions (Calcrim) when it comes to reasonable doubt. In addition, we found significant differences between the Calcrim and the Caljic conditions for the RLAQ. Those participants in the Caljic condition who were high on the RLAQ attitudes of authoritarianism were less likely to comprehend the juror instructions of reasonable doubt and evidence. Our findings demonstrate that juror attitudes work in combination with juror instructions to affect comprehension and that the new instructions (Calcrim) appear to negate this influence.

\section{Limitations and Future Directions}

Perhaps the most limiting aspect of this empirical design was that it was not used with an actual juror sample (venire persons). Though all participants were 18 years of age and older and are eligible to be called for jury duty, this sample is not representative of the California jury pool-specifically with regards to age (mean age $=20.41)$ and socioeconomic background (college students). Still, research has shown that empirical legal research using college student samples is valid for juror decision making research [32].

Another limitation to this study include the lack of a standardized test for measuring comprehension of legal terms, the number of questions for each legal term used, and the type of questions assessing comprehension. The type of question used to assess knowledge of legal terminology was in the true or false format and may not be sensitive enough to capture differences between groups, such as Likert type scale questions. Future studies may want to consider standardizing a properly constructed scale for these legal terms. In addition, presenting these materials in a more ecologically valid environment, such as courtroom videos and story based questions may be warranted to better represent the courtroom environment.

In the future, research on juror comprehension of legal terminology should focus on the development of standardized tests. The formation of standardized tests, for such legal terms as "types of evidence" and "reasonable doubt", would enable future researchers and law makers to better understand and address the 
inadequacies in juror comprehension of criminal jury instructions across the United States, as these legal terms should be comprehended universally by all jurors.

\section{Conclusion}

The newer version of California's criminal jury instructions may actually lead to increased juror comprehension of basic legal terms, as compared to the older version of criminal jury instructions. The use of patterned or standardized state criminal jury instructions enables judge's to spend less time writing and explaining the law to jurors. At the same time, these same jury instructions should enable venire persons to accurately apply the law in each specific criminal case. Research into the comprehension of the law by venire persons should continue to ensure that innocent people are not wrongfully imprisoned and guilty individuals are not set free to recommit crimes against society.

\section{References}

[1] Charrow, R.P. and Charrow, V.R. (1979) Making Legal Language Understandable: A Psycholinguistic Study of Jury Instructions. Columbia Law Review, 79, 13061374. https://doi.org/10.2307/1121842

[2] Elwork, A., Sales, B.D. and Alfini, J.J. (1977) Juridic Decisions: In Ignorance of the Law or in Light of It? Law and Human Behavior, 1, 163-189. https://doi.org/10.1007/BF01053437

[3] Severance, L.J., Greene, E. and Loftus, E.F. (1984) Toward Criminal Jury Instructions That Jurors Can Understand. The Journal of Criminal Law and Criminology, 75, 198-233. https://doi.org/10.2307/1143210

[4] Tiersma, P.M. and Curtis (2008) Testing the Comprehensibility of Jury Instructions: California's Old and New Instructions on Circumstantial Evidence. Journal of Court Innovation, 1, 231-261.

[5] Ellsworth, P.C. and Reifman, A. (2000) Juror Comprehension and Public Policy: Perceived Problems and Proposed Solutions. Psychology, Public Policy, and Law, 6, 788-821. https://doi.org/10.1037/1076-8971.6.3.788

[6] American Bar Association (1999) Perceptions of the US Justice System Executive Summary. Retrieved October 14, 2012. http://www.abanet.org/media/perception/perceptexec.html

[7] Imwinkelried, E.J. and Schwed, L.R. (1987) Guidelines for Drafting Jury Instructions: An Introduction to the Use of Psycholinguistics. Criminal Law Bulletin, 23, 135-150.

[8] Plainlanguage.gov. Improving Communication from the Federal Government to the Public at PlainLanguage.gov. Retrieved October 14, 2008. http://www.plainlanguage.gov/examples/before_after/jury.cfm

[9] Holland, J. (1988) Effective Legal Writing: Who Put the Ease in Legalese? Trial, 24, 56-57.

[10] Tiersma, P.M. (2005) Communicating with Juries: How to Draft More Understandable Instructions. The Scribes Journal of Legal Writing, 10, 1-54.

[11] Goodman, J. and Greene, E. (1989) The Use of Paraphrase Analysis in the Simplification of Jury Instructions. Journal of Social Behavior and Personality, 4, 237-251.

[12] Dane, F.C. (1985) In Search of Reasonable Doubt: A Systematic Examination of Se- 
lected Quantification Approaches. Law and Human Behavior, 9, 141-158. https://doi.org/10.1007/BF01067048

[13] Otto, C.W., Applegate, B.K. and Davis, R.K. (2007) Improving Comprehension of Capital Sentencing Instructions. Crime and Delinquency, 53, 502-517. https://doi.org/10.1177/0011128706294681

[14] Chomsky, N. (2005) Three Factors in Language Design. Linguistic Inquiry, 36, 1-22. https://doi.org/10.1162/0024389052993655

[15] Hemmens, C., Scarborough, K.E. and del Carmen, R.V. (1997) Grave Doubts about Reasonable Doubt: Confusion in State and Federal Courts. Journal of Criminal Justice, 25, 231-254. https://doi.org/10.1016/S0047-2352(97)00008-1

[16] Greene, E., Chopra, S.R., Kovera, M.B., Penrod, S.D., Rose, V.D., Schuller, R. and Studebaker, C.A. (2002) Jurors and Juries: A Review of the Field. In: Ogloff, J.R.P., Ed., Taking Psychology and Law into the Twenty-First Century, Kluwer Academic/Plenum, New York, 225-284.

[17] Hurt, L.E. (1999) Juror Decision Making in Capital Murder Trials: A Social Cognitive Exploration of Guided Discretion. Unpublished Doctoral Dissertation, Graduate School of Saint Louis University, Saint Louis.

[18] Easley, D.F. (2004) “Plain English” Jury Instructions: Why They're Still Needed and What the Appellate Community Can Do to Help. Florida Bar Journal, 78, 66-70.

[19] Kramer, G. and Koenig, D. (1990) Do Jurors Understand Criminal Jury Instructions? Analyzing the Results of the Michigan Juror Comprehension Project. The University of Michigan Journal of Law Reform, 23, 401-437.

[20] Stewart, J.B. (2001) Race, Science, and Just-Us: Understanding Juror's Reasonable Doubt in the OJ Simpson Trial. The Black Scholar, 25, 43-45.

[21] Finkel, N.J. (2000) Commonsense Justice and Jury Instructions: Instructive and Reciprocating Connections. Psychology, public Policy, and Law, 3, 591-628. https://doi.org/10.1037/1076-8971.6.3.591

[22] Lexis Nexis (2005) California Jury Pool Prefers New Plain-English Instructions, Survey Finds; Thirty-One Percent of Prospective Jurors Look forward to Being Called to Duty by Business Wire (16 November 2005).

[23] Allen, M., Mabry, E. and McKelton, D.M. (1998) Impact of Juror Attitudes about the Death Penalty on Juror Evaluations of Guilt and Punishment: A Meta-Analysis. Law and Human Behavior, 22, 715-731. https://doi.org/10.1023/A:1025763008533

[24] Cohn, E.S. and Modecki, K.L. (2007) Gender Differences in Predicting Delinquent Behavior: Do Individual Differences Matter? Social Behavior and Personality, 35, 359-374. https://doi.org/10.2224/sbp.2007.35.3.359

[25] Espinoza, R.K.E. and Willis Esqueda, C. (2008) Defendant and Defense Attorney Characteristics and Their Effects on Juror Decision Making and Prejudice against Mexican-Americans. The Journal of Cultural Diversity and Ethnic Minority Psychology, 14, 364-371. https://doi.org/10.1037/a0012767

[26] Espinoza, R.K.E. and Willis-Esqueda, C. (2014) The Influence of Defendant's Mitigating Information, Race and SES on Death Penalty Decisions by European American and Hispanic Venire Persons. Cultural Diversity and Ethnic Minority Psychology, 21, 288-299. https://doi.org/10.1037/a0037646

[27] Rendell, J.A., Huss, M.T. and Jensen, M.L. (2010) Expert Testimony and the Effects of a Biological Approach, Psychopathy, and Juror Attitudes in Cases of Insanity. Behavioral Sciences and the Law, 28, 411-425. https://doi.org/10.1002/bsl.913

[28] Martin, T.A. and Cohn, E.S. (2004) Attitudes toward the Criminal Legal System: Scale Development and Predictors. Psychology, Crime and Law, 10, 367-391. 
https://doi.org/10.1080/10683160310001629265

[29] Schiffhauer, K. and Wrightsman, S. (1995) The Measurement of Attitudes toward the Legal System. Unpublished Paper, Department of Psychology, University of Kansas, Lawrence.

[30] Kravitz, D.A., Cutler, B.L. and Brock, P. (1993) Reliability and Validity of the Original and Revised Legal Attitudes Questionnaire. Law and Human Behavior, 17, 661677. https://doi.org/10.1007/BF01044688

[31] Wright, D.B. and Hall, M. (2007) How a Reasonable Doubt Instruction Affects Decisions of Guilt. Basic and Applied Social Psychology, 29, 91-98. https://doi.org/10.1080/01973530701331254

[32] Bornstein, B. (1999) The Ecological Validity of Jury Simulations: Is the Jury Still Out? Law and Human Behavior, 23, 75-91. https://doi.org/10.1023/A:1022326807441

Submit or recommend next manuscript to OALib Journal and we will provide best service for you:

- Publication frequency: Monthly

- 9 subject areas of science, technology and medicine

- Fair and rigorous peer-review system

- Fast publication process

- Article promotion in various social networking sites (LinkedIn, Facebook, Twitter, etc.)

- Maximum dissemination of your research work

Submit Your Paper Online: Click Here to Submit

Or Contact service@oalib.com 